\title{
Correlation between Sperm Parameters and Protein Expression of Antioxidative Defense Enzymes in Seminal Plasma: A Pilot Study
}

\author{
Biljana Macanovic, ${ }^{1}$ Milica Vucetic, ${ }^{2}$ Aleksandra Jankovic, ${ }^{2}$ Ana Stancic, ${ }^{2}$ \\ Biljana Buzadzic, ${ }^{2}$ Eliana Garalejic, ${ }^{1}$ Aleksandra Korac, ${ }^{3}$ Bato Korac, ${ }^{2}$ and Vesna Otasevic ${ }^{1}$ \\ ${ }^{1}$ The Clinic of Gynecology and Obstetrics "Narodni front", 11000 Belgrade, Serbia \\ ${ }^{2}$ Department of Physiology, Institute for Biological Research "Sinisa Stankovic”, University of Belgrade, 11000 Belgrade, Serbia \\ ${ }^{3}$ Institute of Zoology and Center for Electron Microscopy, Faculty of Biology, University of Belgrade, 11000 Belgrade, Serbia
}

Correspondence should be addressed to Vesna Otasevic; vesna@ibiss.bg.ac.rs

Received 12 September 2014; Accepted 8 January 2015

Academic Editor: Fabrizia Bamonti

Copyright (C) 2015 Biljana Macanovic et al. This is an open access article distributed under the Creative Commons Attribution License, which permits unrestricted use, distribution, and reproduction in any medium, provided the original work is properly cited.

\begin{abstract}
Background. Semen analysis is the cornerstone in the evaluation of male (in)fertility. However, there are men with normal semen tests but with impaired fertilizing ability, as well as fertile men with poor sperm characteristics. Thus, there is rising interest to find novel parameters that will help to predict and define the functional capacity of spermatozoa. Methods. We examined whether there is a correlation between semen parameters (count, progressive motility, and morphology) and protein expression/activity of antioxidative defense enzymes in seminal plasma from 10 normospermic subjects. Results. Sperm progressive motility was in positive correlation with seminal plasma protein expression of both superoxide dismutase (SOD) isoforms (MnSOD and CuZnSOD) and catalase. Also, positive correlation was observed between sperm count and MnSOD protein expression, as well as between sperm morphology and protein expression of catalase in seminal plasma. In contrast, protein expression of glutathione peroxidase was not in correlation with any sperm parameter, while its activity negatively correlated with sperm morphology and motility. Conclusions. These data suggest that evaluation of protein expression of antioxidative defense enzymes in seminal plasma might be of importance in the evaluation of male fertility status and that could be used as an additional biomarker along with classic semen analysis in assessment of semen quality.
\end{abstract}

\section{Introduction}

Infertility is one of the most serious medical problems worldwide. There has been dramatic increase in male infertility over the last years, and many experts in the field predict that infertility rate could double over the next decade. Nearly $40 \%$ of the issues involved with infertility are attributable to a male factor [1]. Modern lifestyle and social and environmental factors account for part of the decrease in male reproductive capability.

Fundamental parameters that ascertain the functional ability of spermatozoa are sperm count, motility, and sperm morphology [2]. Analysis of these parameters is commonly used to determine/predict fertility status of the men. Most men investigated for infertility have lower-than-normal number of sperms in the semen, or adequate number, but reduced sperm motility (asthenozoospermia), abnormal morphology (teratozoospermia), or combination of both. However, almost $30 \%$ of the male factor infertility cases have no known cause, indicating the lack of sensitive semen tests for the diagnosis of infertility. In addition, there are men with normal semen tests (normozoospermia) but with impaired fertilizing ability of the sperm and inability to achieve pregnancy. On the other hand, there are men with poor sperm characteristics who have no problem to achieve fertilization. This clearly points out that evaluation of fertilizing potential based only on semen parameters is not sufficient to determine fertility status of the men. From the above it arises also that etiology of 
TABLE 1: The mean participant's age and semen parameters.

\begin{tabular}{lccc}
\hline Parameters & $\begin{array}{c}\text { Average } \pm \\
\text { S.E.M. } \\
\text { (of 10 samples) }\end{array}$ & Min/max & Lower reference limit \\
\hline Age of donors (y) & $31.80 \pm 1.82$ & $25 / 34$ & NA \\
Abstinence time (day) & $4.10 \pm 0.44$ & $3 / 5$ & 2 \\
Volume of semen (mL) & $3.37 \pm 0.19$ & $2.5 / 4.5$ & 1.5 \\
Number of spermatozoa $\left(* 10^{6} / \mathrm{mL}\right)$ & $81.90 \pm 8.84$ & $30 / 130$ & $>15$ \\
Motility $(\%)$ & $60.00 \pm 2.01$ & $50 / 70$ & $>40$ \\
Normal morphology $(\%)$ & $36.60 \pm 2.09$ & $30 / 50$ & $>4$ \\
Number of leukocytes & $3.10 \pm 0.69$ & $2 / 6$ & $<6$ \\
Number of erythrocytes & $(-)$ absent & $(-)$ absent & $(-)$ absent \\
\hline
\end{tabular}

infertility is poorly understood and that events on molecular level in both spermatozoa and seminal plasma could be important for male infertility.

For these reasons, one of the most important aims in reproductive biology today is determination of new potential biomarkers of male infertility. It has been shown recently that seminal plasma proteins could serve as important biomarkers for male infertility [3]. In addition, functional proteomic analysis revealed proteins that are over- or underexpressed in the seminal plasma of men with poor semen quality.

Among proteins necessary for sperm function and survival, seminal plasma is endowed with numerous enzymatic antioxidants such as superoxide dismutase (SOD), catalase and glutathione peroxidase (GSH-Px), and a variety of nonenzymatic antioxidants such as ascorbate, urate, $\alpha$ tocopherol, pyruvate, and less amounts of glutathione. This protection compensates for the loss of cytoplasmic sperm enzymes that occurs during maturation and transportation processes, resulting in diminution of the spermatozoa's endogenous enzymatic and repair defenses [4-7].

Different studies have investigated relationship between the seminal plasma antioxidative enzymes and sperm motility as well as specific ejaculate pathologies, that is, quality, but the results are controversial $[4,8-15]$ and, up to now, such lack of consensus keeps the debate open.

In line with this, in this pilot study we try to gain insight on the mechanisms of male infertility from the perspective of the possible importance of protein expression profile of antioxidative defense (AD) enzymes in seminal plasma and spermatozoa functional parameters.

\section{Materials and Methods}

2.1. Samples. The Ethic Committee of the Clinic for Gynecology and Obstetrics "Narodni front" and of the Institute for Biological Research at the University of Belgrade approved the study. Semen samples from ten subjects, who signed an informed consent, were classified as normospermic, according to criteria established by the WHO [2]. The mean of participants' age and semen parameters are summarized in Table 1 . These subjects were recruited from couples applying for reproductive technology procedures at the Artificial Reproductive Technology Department of the Clinic for Gynecology and Obstetrics "Narodni front", Belgrade, Republic of Serbia, with an infertility caused by woman's factor. The seminal samples were obtained by masturbation after 3-5 days of abstinence. After complete liquefaction (average time $20 \mathrm{~min}$ ), manual semen analysis was performed and clear seminal plasma was separated from the sperm pellet by centrifugation at $3000 \mathrm{~g}$ for 30 minutes to ensure complete removal of the cellular components. The supernatants obtained were aliquoted and stored at $-80^{\circ} \mathrm{C}$ until subsequent analysis.

2.2. SDS-PAGE and Western Blotting. Western blots were conducted as described previously [16], using antibodies against manganese SOD (MnSOD) (ab13533; 1:5000), copper, zinc SOD (CuZnSOD) (ab13498; $0.2 \mathrm{~g} \mathrm{l-1)}$, catalase (ab1877; 1:1000), and GSH-Px (ab16798; 1:2000) (all purchased from Abcam, Cambridge, UK). Quantitative analysis of immunoreactive bands was conducted with ImageQuant software. Volume was the sum of all the pixel intensities within a band, that is, 1 pixel $=0.007744 \mathrm{~mm}^{2}$. We averaged the ratio of dots per band for the target protein in corresponding samples, from three similar independent experiments. Data were then statistically analyzed.

2.3. Activity of AD Enzymes. SOD activity was determined by the method of Misra and Fridovich [17] but at $26^{\circ} \mathrm{C}$ and expressed in $\mathrm{U} \mathrm{mg}^{-1}$ protein. Total specific SOD activity and MnSOD activity after the inhibition with $4 \mathrm{mM}$ KCN were measured and then CuZnSOD activity was calculated. SOD units were defined as the amount of the enzyme inhibiting epinephrine oxidation by $50 \%$ under the appropriate reaction conditions. Catalase was assayed according to Beutler [18] and the activity expressed in $\mu \mathrm{mol} \mathrm{H}_{2} \mathrm{O}_{2} \mathrm{~min}^{-1} \mathrm{mg}^{-1}$ protein. GSH-Px was determined using $t$-butylhydroperoxide as a substrate [19] and the activity expressed in nmol NADPH $\mathrm{min}^{-1} \mathrm{mg}^{-1}$ protein. GST was measured by the method of Habig et al. [20] and the activity is expressed in nM GSH $\mathrm{min}^{-1} \mathrm{mg}^{-1}$ protein.

2.4. Additional Assays and Statistical Analysis. Protein content was estimated using bovine serum albumin as reference protein [21]. Pearson correlation coefficient was used to 
TABLE 2: Correlation between sperm parameters and relative protein expression of antioxidative enzymes in seminal plasma.

\begin{tabular}{|c|c|c|c|c|}
\hline & CuZnSOD & MnSOD & GSH-Px & Catalase \\
\hline Number of spermatozoa $\left(\times 10^{6}\right)$ & $\begin{array}{c}r=0.538 \\
P=0.109 \\
\text { NS }\end{array}$ & $\begin{aligned} r & =0.843 \\
P & =0.002 \\
& * * *\end{aligned}$ & $\begin{array}{c}r=0.359 \\
P=0.308 \\
\quad \text { NS }\end{array}$ & $\begin{array}{c}r=0.502 \\
P=0.139 \\
\text { NS }\end{array}$ \\
\hline Progressive motility of spermatozoa (\%) & $\begin{array}{c}r=0.908 \\
P=0.0003 \\
* * *\end{array}$ & $\begin{aligned} r & =0.797 \\
P & =0.006 \\
& * * *\end{aligned}$ & $\begin{array}{c}r=0.403 \\
P=0.248 \\
\text { NS }\end{array}$ & $\begin{aligned} r & =0.789 \\
P & =0.007 \\
& * * *\end{aligned}$ \\
\hline Morphology of spermatozoa (\%) & $\begin{array}{c}r=0.434 \\
P=0.210 \\
\text { NS }\end{array}$ & $\begin{array}{c}r=0.307 \\
P=0.388 \\
\text { NS }\end{array}$ & $\begin{array}{c}r=-0.118 \\
P=0.248 \\
\text { NS }\end{array}$ & $\begin{aligned} r= & 0.603 \\
P= & 0.066 \\
& *\end{aligned}$ \\
\hline
\end{tabular}

$\mathrm{CuZn/Mn} \mathrm{SOD,} \mathrm{CuZn/Mn} \mathrm{superoxide} \mathrm{dismutase;} \mathrm{GSH-Px,} \mathrm{glutathione} \mathrm{peroxidase.}$

Significance: NS, not significant; ${ }^{*} P<0.1 ;{ }^{* * *} P<0.01$.

evaluate the relationship of $\mathrm{AD}$ enzymes protein expression/activity with different sperm parameters. All data are presented as mean \pm S.E.M. $P$ values less than 0.05 were considered statistically significant.

\section{Results}

Table 2 shows positive correlation $(r=0.843, P<0.01)$ between spermatozoa count per $\mathrm{mL}$ and protein expression of MnSOD in seminal plasma of corresponding samples. Also, a strong positive correlation between sperm progressive motility and protein expression of CuZnSOD $(r=0.908, P<$ $0.01)$, MnSOD $(r=0.797, P<0.01)$, and catalase $(r=0.789$, $P<0.01)$ as well as between sperm morphology and protein expression of catalase in seminal plasma of corresponding samples $(r=0.603, P<0.1)$ is shown in Table 2 .

Table 3 summarizes relationship between sperm parameters and activity of antioxidant enzymes in seminal plasma of corresponding samples. Highly negative relationship was observed between seminal plasma GSH-Px activity and sperm progressive motility $(r=-0.705, P<0.05)$, that is, morphology $(r=-0.601, P<0.1)$.

\section{Discussion}

In the present pilot study we have shown that protein expression of CuZnSOD, MnSOD, and catalase in seminal plasma is in strong positive correlation with some of semen quality parameters. Also, negative relationship between seminal plasma GSH-Px activity and sperm morphology and progressive motility has been shown. These data shed a new light on odd players, seminal plasma antioxidative components, as potential molecular markers of male fertility status.

Relationship between the seminal plasma antioxidative enzymes activity and sperm quality has been investigated so far, but the results obtained are controversial [4, 8-15]. Our finding of negative correlation between seminal plasma GSHPx activity and sperm morphology is supported by the data of Atig et al. [22]. On the other hand, negative correlation between seminal plasma GSH-Px activity and sperm motility detected in our study is in discordance with the data reported by the same authors [22]. Opposite relationship, that is,
TABLE 3: Correlation between sperm parameters and activity of antioxidative enzymes in seminal plasma.

\begin{tabular}{lccc}
\hline & CuZnSOD & GSH-Px & GST \\
\hline Number of & $r=0.094$ & $r=-0.179$ & $r=0.422$ \\
spermatozoa & $P=0.796$ & $P=0.621$ & $P=224$ \\
$\left(\times 10^{6}\right)$ & $\mathrm{NS}$ & $\mathrm{NS}$ & $\mathrm{NS}$ \\
\hline Progressive & $r=0.288$ & $r=-0.705$ & $r=0.255$ \\
motility of & $P=0.420$ & $P=0.023$ & $P=0.477$ \\
spermatozoa (\%) & $\mathrm{NS}$ & $* *$ & $\mathrm{NS}$ \\
\hline \multirow{2}{*}{ Morphology of } & $r=0.405$ & $r=-0.601$ & $r=0.314$ \\
spermatozoa $(\%)$ & $P=0.246$ & $P=0.066$ & $P=0.377$ \\
& $\mathrm{NS}$ & $*$ & $\mathrm{NS}$ \\
\hline
\end{tabular}

CuZnSOD, CuZn superoxide dismutase; GSH-Px, glutathione peroxidase; GST, glutathione S-transferase.

Significance: NS, not significant; ${ }^{*} P<0.1 ;{ }^{*} P<0.05$.

positive correlation between seminal plasma GSH-Px activity and sperm quality, was also found by Giannattasio et al. [23], Dandekar et al. [24], and Hsieh et al. [25]. Such variability and controversy of the findings, along with absence of any correlation between sperm parameters and SOD and catalase activity in seminal plasma which is shown here, strongly indicate that the activity of AD enzymes in seminal plasma is not a useful tool in predicting fertilizing status of men, at least in the normospermic samples.

On the other hand, here we have shown very good correlation between protein expressions of $\mathrm{AD}$ enzymes in seminal plasma with semen parameters. Thus, these data suggest that protein expressions of $\mathrm{AD}$ enzymes in seminal plasma could be used as predictor of male fertility status. Namely, we demonstrated positive correlation between protein expression of (a) MnSOD and sperm count and progressive motility, (b) catalase and sperm motility and morphology, and (c) CuZnSOD and sperm morphology. This strong correlation of MnSOD, CuZnSOD, and catalase expression and sperm quality parameters clearly illustrates importance of these proteins (at least some of them) in male (in)fertility. In the light of recently shown importance of seminal plasma proteins in sperm functioning, these data might be very important and certainly warrant the attention, in terms of molecular markers of male infertility, in particular.

This is noteworthy from the standpoint of finding new approach in determining semen quality apart of semen 
analysis, that is, increasing number of factors that can provide information about semen quality, especially in the case of idiopathic male infertility. In addition, this also could be helpful for selection of the most potent spermatozoa for in vitro fertilization and subsequent improvement of assisted fertilization outcome. One more important fact is that protein expression of $\mathrm{AD}$ enzymes in seminal plasma is determined by Western blot that is noninvasive, simple, and easy applicable method in most labs.

In general, presented data suggest that evaluation of protein expression of $\mathrm{AD}$ enzymes in seminal plasma might be of prognostic importance in the evaluation of male fertility status and that could be used as an additional biomarker along with classic semen analysis in assessment of semen quality. We believe that these data will help the development of new approaches to diagnose and treat male infertility. Certainly, further study using larger sample size, spermatozoa with different pathologies, and semen samples from infertile men is needed to validate these findings.

\section{Conflict of Interests}

All authors declare no competing interests.

\section{Authors' Contribution}

Biljana Macanovic recruited subjects, performed experiments, and drafted paper. Milica Vucetic performed experiments and statistical analysis and revised paper. Aleksandra Jankovic revised paper. Ana Stancic revised paper. Biljana Buzadzic helped to draft paper. Eliana Garalejic recruited subjects. Aleksandra Korac participated in study design and interpreted data. Bato Korac designed experiments, helped to draft paper, and critically revised paper. Vesna Otasevic designed and performed experiments, interpreted data, and drafted paper. All authors read and approved the final paper.

\section{Acknowledgments}

This work was supported by the Ministry of Education, Science and Technological Development of the Republic of Serbia, Grant no. 173054, and by the COST BM1203.

\section{References}

[1] B. Buzadzic, M. Vucetic, A. Jankovic et al., "New insights into male (in)fertility: the importance of NO," British Journal of Pharmacology, 2014.

[2] World Health Organization, WHO Laboratory Manual For The Examination And Processing Of Human Semen, Cambridge University Press, Cambridge, UK, 5th edition, 2010.

[3] R. Sharma, A. Agarwal, G. Mohanty et al., "Functional proteomic analysis of seminal plasma proteins in men with various semen parameters," Reproductive Biology and Endocrinology, vol. 11, no. 1, article 38, 2013.

[4] T. Kobayashi, T. Miyazaki, M. Natori, and S. Nozawa, "Protective role of superoxide dismutase in human sperm motility: superoxide dismutase activity and lipid peroxide in human seminal plasma and spermatozoa," Human Reproduction, vol. 6, no. 7, pp. 987-991, 1991.

[5] O. F. Padron, C. M. Lynne, N. L. Brackett, A. J. Thomas Jr., R. K. Sharma, and A. Agarwal, "Seminal reactive oxygen species and sperm motility and morphology in men with spinal cord injury," Fertility and Sterility, vol. 67, no. 6, pp. 1115-1120, 1997.

[6] M. Ollero, E. Gil-Guzman, M. C. Lopez et al., "Characterization of subsets of human spermatozoa at different stages of maturation: implications in the diagnosis and treatment of male infertility," Human Reproduction, vol. 16, no. 9, pp. 1912-1921, 2001.

[7] J. Fujii, Y. Iuchi, S. Matsuki, and T. Ishii, "Cooperative function of antioxidant and redox systems against oxidative stress in male reproductive tissues," Asian Journal of Andrology, vol. 5, no. 3, pp. 231-242, 2003.

[8] A. Zini, E. de Lamirande, and C. Gagnon, "Reactive oxygen species in semen of infertile patients: levels of superoxide dismutase- and catalase-like activities in seminal plasma and spermatozoa," International Journal of Andrology, vol. 16, no. 3, pp. 183-188, 1993.

[9] D. Sanocka, R. Miesel, P. Jedrzejczak, and M. K. Kurpisz, "Oxidative stress and male infertility," Journal of Andrology, vol. 17, no. 4, pp. 449-454, 1996.

[10] S. A. Suleiman, M. E. Ali, Z. M. S. Zaki, E. M. A. El-Malik, and M. A. Nasr, "Lipid peroxidation and human sperm motility: protective role of vitamin E," Journal of Andrology, vol. 17, no. 5, pp. 530-537, 1996.

[11] I. Alkan, F. Şimşek, G. Haklar et al., "Reactive oxygen species production by the spermatozoa of patients with idiopathic infertility: relationship to seminal plasma antioxidants," Journal of Urology, vol. 157, no. 1, pp. 140-143, 1997.

[12] M. Jóźwik, M. Jóźwik, W. Kuczyński, and M. Szamatowicz, "Nonenzymatic antioxidant activity of human seminal plasma," Fertility and Sterility, vol. 68, no. 1, pp. 154-157, 1997.

[13] S. E. M. Lewis, E. S. L. Sterling, I. S. Young, and W. Thompson, "Comparison of individual antioxidants of sperm and seminal plasma in fertile and infertile men," Fertility and Sterility, vol. 67, no. 1, pp. 142-147, 1997.

[14] R. Miesel, P. Jedrzejczak, D. Sanocka, and M. K. Kurpisz, "Severe antioxidase deficiency in human semen samples with pathological spermiogram parameters," Andrologia, vol. 29, no. 2, pp. 77-83, 1997.

[15] D. Sanocka, R. Miesel, P. Jȩdrzejczak, A. Chełmonskasoyta, and M. Kurpisz, "Effect of reactive oxygen species and the activity of antioxidant systems on human semen; Association with male infertility," International Journal of Andrology, vol. 20, no. 5, pp. 255-264, 1997.

[16] V. Petrović, A. Korać, B. Buzadžić, and B. Korać, "The effects of $\mathrm{L}$-arginine and L-NAME supplementation on redox-regulation and thermogenesis in interscapular brown adipose tissue," Journal of Experimental Biology, vol. 208, no. 22, pp. 4263-4271, 2005.

[17] H. P. Misra and I. Fridovich, "The role of superoxide anion in the autoxidation of epinephrine and a simple assay for superoxide dismutase., Journal of Biological Chemistry, vol. 247, no. 10, pp. 3170-3175, 1972.

[18] E. Beutler, "Catalase," in Red Cell Metabolism: A Manual of Biochemical Methods, E. Beutler, Ed., pp. 105-106, Grune \& Stratton, Inc., New York, NY, USA, 1982. 
[19] D. E. Paglia and W. N. Valentine, "Studies on the quantitative and qualitative characterization of erythrocyte glutathione peroxidase," Journal of Laboratory and Clinical Medicine, vol. 70, no. 1, pp. 158-169, 1967.

[20] W. H. Habig, M. J. Pabst, and W. B. Jakoby, "Glutathione-Stransferases," Journal of Biological Chemistry, vol. 249, no. 22, pp. 7130-7139, 1974.

[21] O. H. Lowry, N. J. Rosebrough, A. L. Farr, and R. J. Randall, "Protein measurement with the Folin phenol reagent," The Journal of Biological Chemistry, vol. 193, no. 1, pp. 265-275, 1951.

[22] F. Atig, M. Raffa, H. B. Ali, K. Abdelhamid, A. Saad, and M. Ajina, "Altered antioxidant status and increased lipid peroxidation in seminal plasma of Tunisian infertile men," International Journal of Biological Sciences, vol. 8, no. 1, pp. 139-149, 2011.

[23] A. Giannattasio, M. de Rosa, R. Smeraglia et al., "Glutathione peroxidase (GPX) activity in seminal plasma of healthy and infertile males," Journal of Endocrinological Investigation, vol. 25, no. 11, pp. 983-986, 2002.

[24] S. P. Dandekar, G. D. Nadkarni, V. S. Kulkarni, and S. Punekar, "Lipid peroxidation and antioxidant enzymes in male infertility," Journal of Postgraduate Medicine, vol. 48, no. 3, pp. 186-189, 2002.

[25] Y.-Y. Hsieh, C.-C. Chang, and C.-S. Lin, "Seminal malondialdehyde concentration but not glutathione peroxidase activity is negatively correlated with seminal concentration and motility," International Journal of Biological Sciences, vol. 2, no. 1, pp. 2329, 2006. 


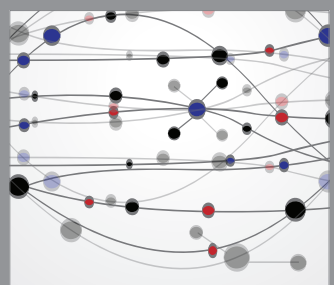

The Scientific World Journal
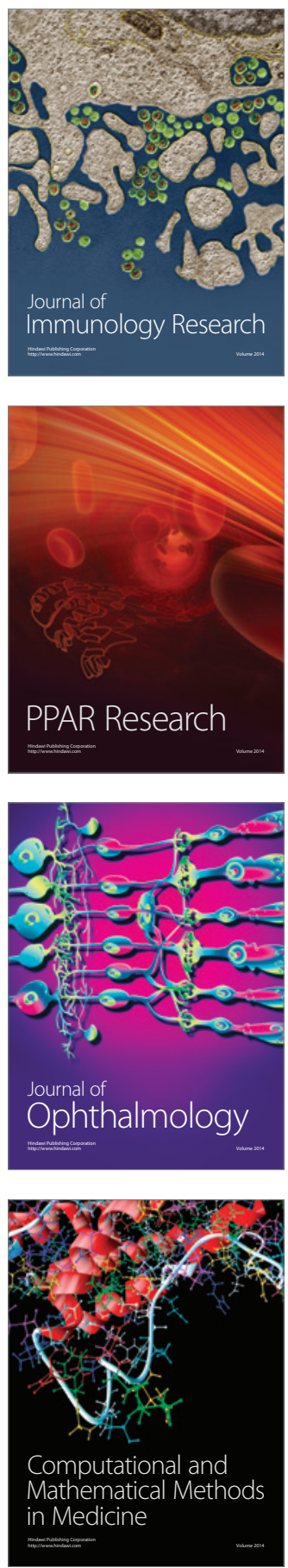

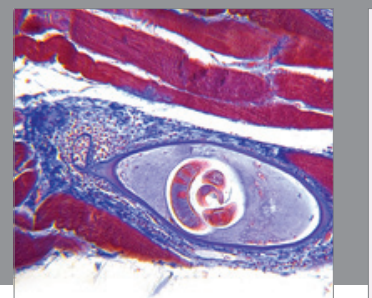

Gastroenterology

Research and Practice
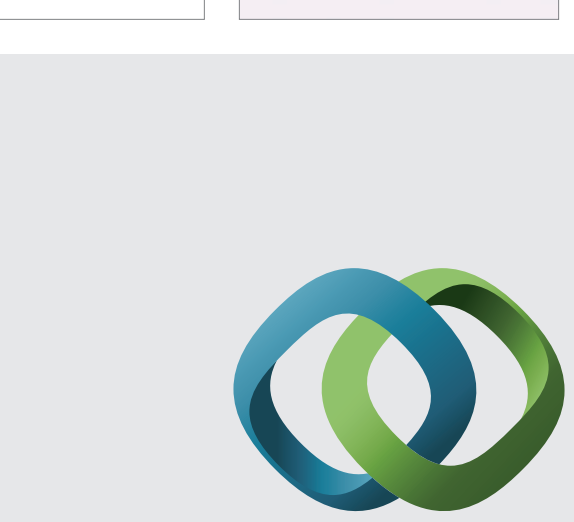

\section{Hindawi}

Submit your manuscripts at

http://www.hindawi.com
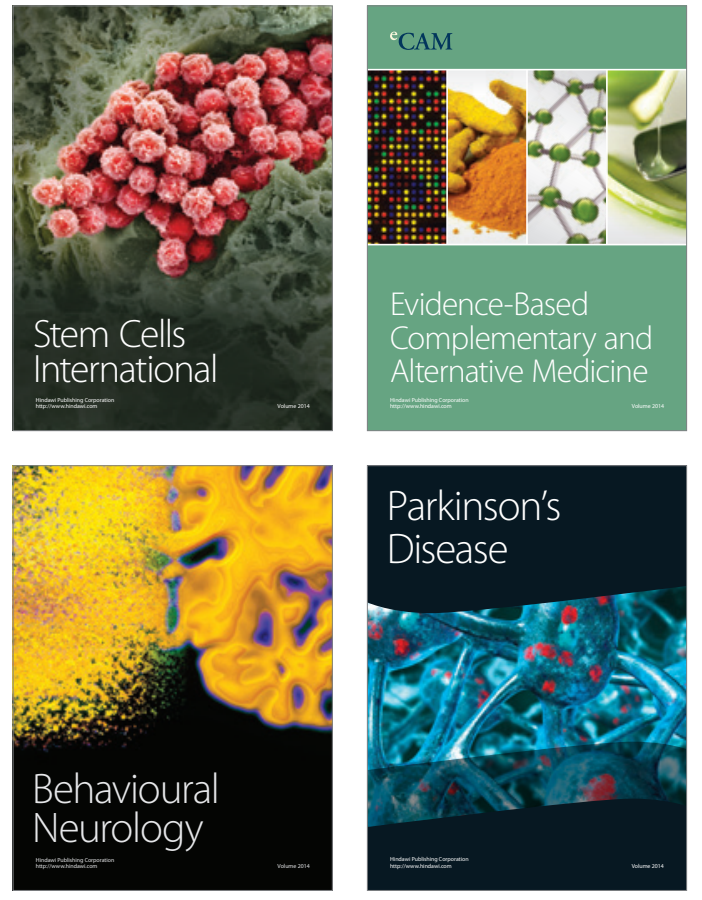
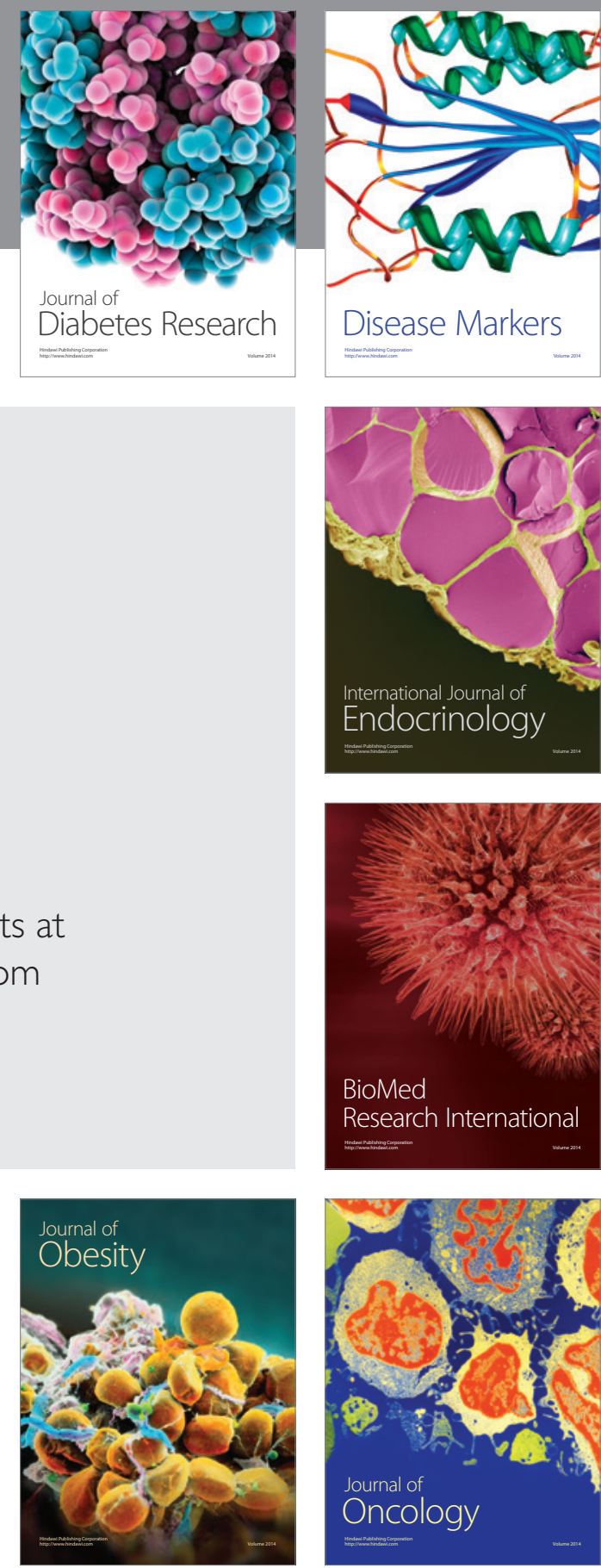

Disease Markers
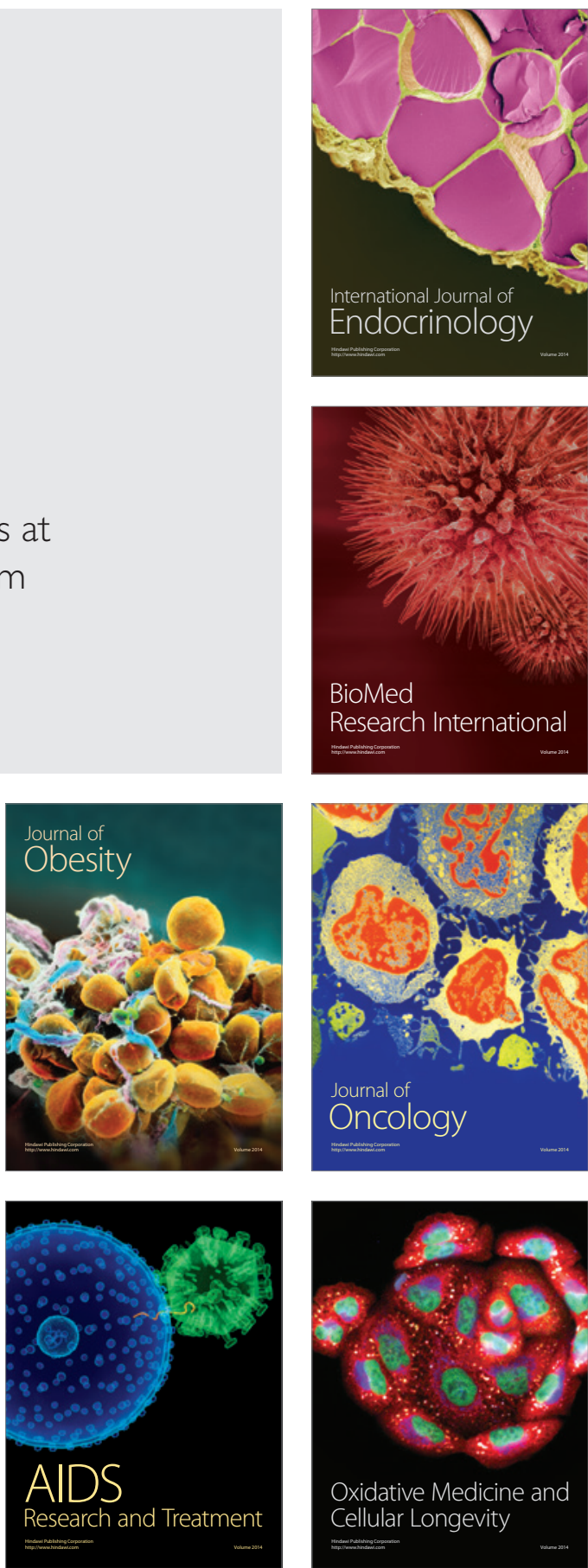